Patients in the splenectomy group refused red cell survival studies after operation.

Throughout the years after partial splenic embolisation the spleens remained about one third of their original size. A transient, small increase in size was observed during the first month after the procedure. Liver size remained unchanged in both groups of patients.

Patients treated by partial splenic embolisation remained free of serious infections or other illnesses during follow up and showed almost normal puberty and growth. By contrast, two of the patients with splenectomy suffered recurrent infections.

\section{Discussion}

Successful partial splenic embolisation in other diseases ${ }^{5}$ encouraged us to use this procedure for patients with thalassaemia major in an attempt to overcome the disadvantages of splenectomy. Partial splenic embolisation was followed by a significant prolongation of red cell survival, while the fall of the transfusion index, though slightly smaller than after splenectomy, was not significantly different from that in the splenectomised controls. That these low transfusion indices remained unchanged throughout the five years of follow up is convincing evidence that the procedure may be an effective alternative to splenectomy in thalassaemia major.

Furthermore, that the amount of residual splenic tissue remained unchanged suggests that regeneration had not taken place and therefore that hypersplenism was unlikely to develop in the near future. Should this assumption prove false further partial splenic embolisation could be carried out. Partial splenic embolisation represents an easily repeatable and accurately titrable procedure. Such a second embolisation was required in one of our patients because the proportion of spleen infarcted the first time was too low.

The normal platelet counts during the years after partial splenic embolisation represent another important advantage of the procedure, by which the threat of postsplenectomy embolisms and the subsequent use of antiplatelet factors might be avoided. Partial splenic embolisation, however, was as effective as splenectomy in correcting pre-existing thrombocytopenia, at least in the one patient in our series with this problem.

The absence of serious recurrent infections in our patients treated by embolisation together with their normal growth suggests that the immune function of the spleen may be preserved by the remaining tissue.

The failure of our patients to achieve a negative iron balance despite the reduction of their transfusion index may be attributed to their overestimating the positive effect of partial splenic embolisation alone and so reducing the iron chelation treatment. The decreasing ferritin concentrations, however, suggest that patients will reach negative iron balance eventually.

In conclusion, the results of this five year follow up suggest that partial splenic embolisation may prove to be a safe and reliable alternative to splenectomy in the management of thalassaemia major.

\section{References}

1 Modell B, Berdoukas V. The clinical approach to thalassaemia. New York: Grune and Stratton, 1984 2 Smith CH, Erlandson ME, Stern G, Hilgartner MW. Postsplenectomy infection in Cooley's anemia. Ann NY Acad Sci 1964;119:748-57.

3 Eraklis AJ, Kevy SV, Diamond LK, Cross RE. Hazard of overwhelming infection after splenectomy in childhood. N Engl F Med 1967;276:1225-9.

4 Fucharoen S. Hypoxaemia and the effect of aspirin in thalassaemia. Southeast Asian $\mathcal{F}$ Trop Med Public Health 1981;12:90-3.

5 Spigos DG, Jonasson O, Mozew M, Capek V. Partial splenic embolization in the treatment of hypersplenism. Am J Roentgenol 1979;132:777-82.

(Accepted 15 January 1987)

\title{
Predictive value of plasma human chorionic gonadotrophin $\beta$ subunit in diagnosing ectopic pregnancy after in vitro fertilisation and embryo transfer
}

\author{
S H OKAMOTO, D L HEALY, L M MORROW, P A W ROGERS, A O TROUNSON, \\ E C WOOD
}

\section{Abstract}

A study was conducted aimed at establishing a range of plasma concentrations of the $\beta$ subunit of human chorionic gonadotrophin that might predict ectopic pregnancy after in vitro fertilisation and embryo transfer. From May 1984 to February 1986, 161 consecutive pregnancies at the Monash University in vitro fertilisation unit were analysed by determining plasma $\beta$ human chorionic gonadotrophin concentrations between two and 10 weeks after oocyte collection. Eighty eight ongoing singleton pregnancies, 25 multiple pregnancies, 27 first trimester spontaneous abortions, 12 anembryonic pregnancies, and nine ectopic pregnancies resulted from these conception cycles. When compared with values for ongoing singleton pregnancies two weeks after oocyte collection plasma $\beta$ human chorionic gonadotrophin concentrations in ectopic pregnancies were significantly lower $(p<0.05$; Wilcoxon rank sum test). Two weeks after oocyte collection all plasma $\beta$ human chorionic gonadotrophin concentrations in the set of ectopic pregnancies were below 30.6 IU/1, which corresponded to the lower quartile (25th percentile) of $\beta$ human chorionic gonadotrophin concentrations in ongoing singleton pregnancies. The $\beta$ human chorionic gonadotrophin concentration corresponding to the lower quartile of ongoing singleton pregnancies at each week of gestation was used to derive the predictive value of various statistics in detecting ectopic pregnancy in patients after in vitro fertilisation. The sensitivity, specificity, predictive value of a positive result, predictive value of a negative result, and efficiency of a single plasma $\beta$ human chorionic gonadotrophin concentration in predicting ectopic pregnancy were $100 \%$, $68 \cdot 1 \%, 16 \cdot 7 \%, 100 \%$, and $70 \%$, respectively, two weeks after oocyte collection.

These results suggest that a single determination of the plasma $\beta$ human chorionic gonadotrophin concentration beginning 14 days after oocyte collection is clinically useful in predicting the outcome of pregnancy achieved by in vitro fertilisation. Ectopic pregnancy after in vitro fertilisation is more likely when $\beta$ human chorionic gonadotrophin concentration is below the lower quartile of values in ongoing singleton pregnancies achieved by the technique.

\section{Introduction}

Ectopic pregnancy is a leading cause of maternal mortality, and reports show that the ratio of ectopic pregnancy to live births 
is increasing. ${ }^{12}$ In vitro fertilisation and embryo transfer were developed as a treatment for infertility in patients with irreparable tubal disease, ${ }^{34}$ and patients who become pregnant after this technique have an incidence of ectopic pregnancy three to five times higher than in a normal population. ${ }^{256}$ Early detection of ectopic pregnancy in patients treated by in vitro fertilisation is critical since further surgery is often difficult. Recent reports have described a discriminatory zone in the plasma concentration of the $\beta$ subunit of human chorionic gonadotrophin (between 6000 and $6500 \mathrm{IU} / \mathrm{l}$ ) which was of value in diagnosing ectopic pregnancy in subjects who conceived spontaneously. ${ }^{78} \beta$ Human chorionic gonadotrophin, however, makes a delayed appearance in the plasma of subjects with ongoing pregnancies achieved by in vitro fertilisation and embryo transfer compared with spontaneous pregnancies, ${ }^{90}$ so the value of $\beta$ human chorionic gonadotrophin measurements in diagnosing ectopic pregnancy in patients after in vitro fertilisation cannot be extrapolated from spontaneous conceptions.

The only report which attempted to examine the predictive value of $\beta$ human chorionic gonadotrophin concentrations in the diagnosis of ectopic pregnancy in patients treated by in vitro fertilisation was an international collaborative study. 6 Unfortunately, that study used parametric statistics in an analysis of $\beta$ human chorionic gonadotrophin concentrations though the data did not follow a Gaussian distribution. Moreover, despite the title of that paper no predictive statistics of $\beta$ human chorionic gonadotrophin concentrations were provided. These omissions are especially disappointing as it is now accepted that predictive statistics have definite clinical value in medical practice. "We report an analysis of 161 consecutive pregnancies resulting from in vitro fertilisation at one centre. The concentrations of plasma $\beta$ human chorionic gonadotrophin from ongoing singleton pregnancies were compared with those from ectopic pregnancies and other types of failed pregnancy to derive predictive statistics applicable to in vitro fertilisation and embryo transfer programmes.

\section{Patients and methods}

The Monash University in vitro fertilisation and embryo transfer programme has been described. ${ }^{412}{ }^{13}$ From May 1984 to February 1986 there were 161 clinical pregnancies in this unit. Clinical information about the outcome of each pregnancy together with surgical and histopathological records were collected and collated. Eighty eight ongoing singleton pregnancies, 25 multiple pregnancies, 27 first trimester spontaneous abortions, 12 anembryonic pregnancies, and nine ectopic pregnancies resulted from these conception cycles. The clinical features of the ectopic pregnancies have been reported. ${ }^{14}$

To diagnose pregnancy all patients provided a $10 \mathrm{ml}$ blood sample 14 days after oocyte retrieval. Plasma $\beta$ human chorionic gonadotrophin was assayed using a three hour radioimmunoassay (Mallinckrodt, St Louis, MA) at room temperature, as described. ${ }^{14}$ Briefly, the interassay coefficients of variation were $8.4 \%$ at $25 \mathrm{IU} / 1$ and $9.9 \%$ at $45 \mathrm{IU} / 1(\mathrm{n}=170)$. The intra-assay coefficients of variation were $6.0 \%$ at $12 \mathrm{IU} / 1$ and $3.9 \%$ at $70 \mathrm{IU} / 1$, and the sensitivity of the radioimmunoassay was $1.7 \mathrm{IU} / 1$.

Patients showing plasma $\beta$ human chorionic gonadotrophin concentrations greater than $1.7 \mathrm{IU} / \mathrm{l}$ two weeks after oocyte aspiration were asked to provide weekly blood samples for $\beta$ human chorionic gonadotrophin determination until 10 weeks after oocyte collection. Biochemical pregnancy was defined if the plasma $\beta$ human chorionic gonadotrophin value was greater than $5 \mathrm{IU} / 1$ and increasing in two consecutive samples one week apart. Of a total of 180 pregnancies defined biochemically, there were 19 early "pregnancies" which developed no clinical signs whatsoever. These were excluded from our analysis, which was confined to clinical pregnancies only.

\section{STATISTICAL ANALYSIS}

A recent international collaborative study examining $\beta$ human chorionic concentrations in pregnancies after in vitro fertilisation and embryo transfer analysed $\beta$ human chorionic gonadotrophin data by determining an arithmetic mean and standard deviation and applying repeated Student's $t$ tests to compare $\beta$ human chorionic gonadotrophin concentrations in abnormal versus normal pregnancies resulting from the technique ${ }^{6}$; we therefore analysed whether the range of plasma $\beta$ human chorionic

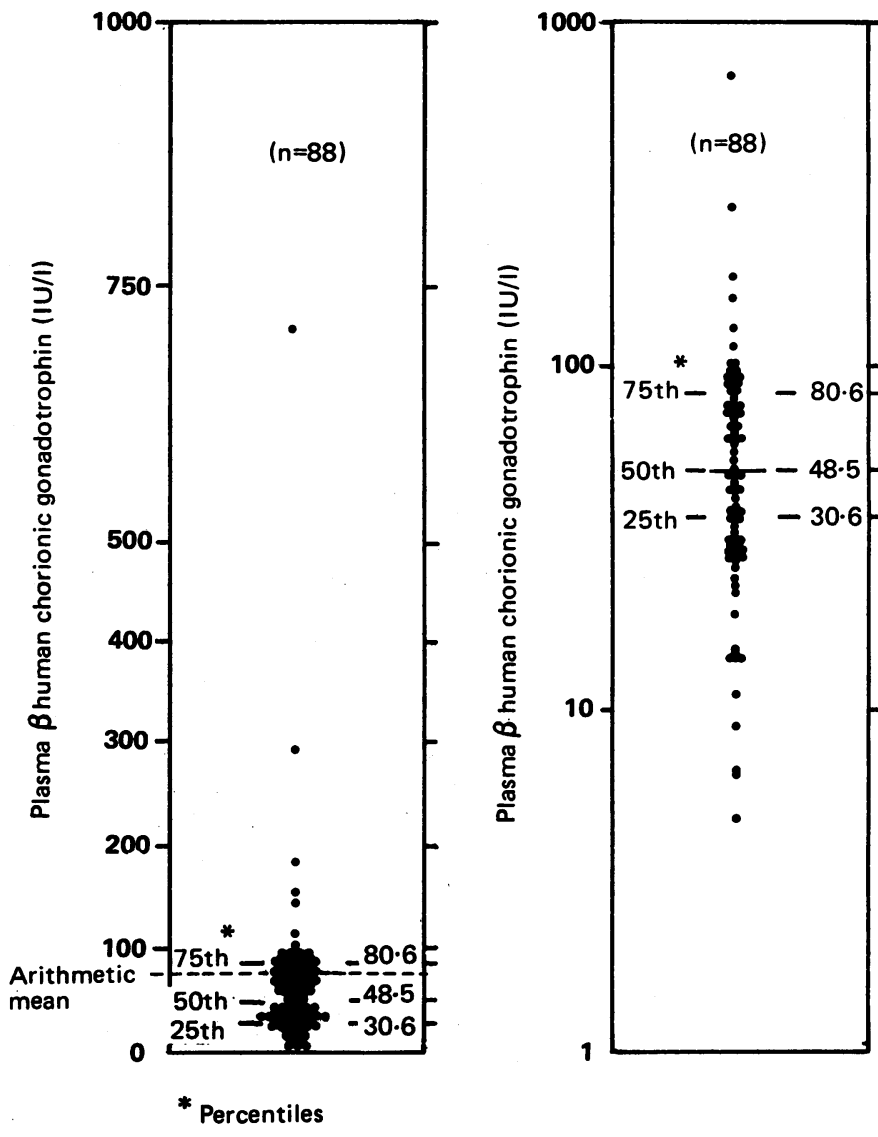

FIG 1 -Plasma $\beta$ human chorionic gonadotrophin concentrations two weeks after oocyte collection in ongoing singleton pregnancies resulting from in vitro fertilisation. $\beta$ Human chorionic gonadotrophin concentrations represented on arithmetic scale (left) and after logarithmic transformation (right).

gonadotrophin concentrations in pregnancies achieved by in vitro fertilisation did indeed follow a normal or Gaussian distribution. Figure 1 shows plasma $\beta$ human chorionic gonadotrophin concentrations two weeks after oocyte collection in ongoing singleton pregnancies achieved by in vitro fertilisation. Clearly the data were greatly skewed when concentrations were plotted on an arithmetic scale. As expected, logarithmic transformation changed the shape of the distribution of the data to a form which was approximately symmetrical (fig 1). Nevertheless, the graphic test for normality did not show linearity of the cumulative frequency distribution and the $\mathrm{G}$ test of goodness of fit for the logarithmically transformed data showed a significant departure from normality $(p<0 \cdot 05)$. (The $G$ test statistic has been favoured over the $\chi^{2}$ test for goodness of fit for single classification frequency distributions as it is computationally simpler, is additive, and may be partitioned into separate tests if necessary..$^{15}$ ) Finally, tests of normality by assessment of the moment statistics of skewness and kurtosis before $(5.83 ; 42.13)$ and after $(-0.08 ; 4.56)$ logarithmic transformation also confirmed pronounced deviation of the data from normality. Hence even logarithmically transformed data were considered inappropriate for analysis of our findings by parametric statistics, and therefore nonparametric methods were subsequently employed..$^{16}$

Wilcoxon's rank sum test ${ }^{15}$ was used to compare $\beta$ human chorionic gonadotrophin concentrations between ongoing singleton pregnancies and ectopic pregnancies in the weeks after oocyte collection. To examine the value of the plasma $\beta$ human chorionic gonadotrophin test in distinguishing ectopic pregnancies from ongoing pregnancies achieved by in vitro fertilisation we determined the sensitivity, specificity, and predictive values of a positive or negative result and the efficiency of the test. ${ }^{17}$ In summary, sensitivity measures the likelihood that the plasma $\beta$ human chorionic gonadotrophin concentration will be positive (abnormal) in the presence of an ectopic pregnancy. Sensitivity is the number of true positive test results divided by the sum of the true positive plus false negative observations. Specificity is the likelihood that the result of the $\beta$ human chorionic gonadotrophin test will be negative (normal) in the absence of an ectopic pregnancy and is given by the number of true negative values divided by the sum of the true negative plus false positive observations. The predictive value of a positive result is the number of true positive observations divided by the sum of true and false positive observations, while the predictive value 
of a negative result is the number of true negative observations divided by the sum of the false negative and true negative observations. Statistical efficiency is the sum of the true positive and true negative results divided by the grand total of observations studied.

TABLE I-Plasma $\beta$ human chorionic gonadotrophin concentrations two to 10 weeks after oocyte collection in 88 single pregnancies achieved by in vitro fertilisation

\begin{tabular}{crrrrrrrr}
\hline $\begin{array}{c}\text { Weeks after } \\
\text { oocyte } \\
\text { collection }\end{array}$ & \multicolumn{6}{c}{ Percentile of plasma $\beta$ human chorionic gonadotrophin concentration (IU/l) } \\
\cline { 2 - 9 } & Maximum & 95 & 75 & 50 & 25 & 5 & Minimum \\
\hline 2 & 705 & 131 & $80 \cdot 6$ & $48 \cdot 5$ & $30 \cdot 6$ & $10 \cdot 6$ & $4 \cdot 8$ \\
3 & 25400 & 4100 & 1800 & 950 & 607 & $137 \cdot 3$ & $37 \cdot 1$ \\
4 & 27400 & 20500 & 11675 & 7700 & 4900 & 1475 & 304 \\
5 & 90000 & 56210 & 37550 & 27100 & 17200 & 7530 & 1800 \\
6 & 118700 & 94800 & 67100 & 48000 & 34600 & 18920 & 11700 \\
7 & 218000 & 101400 & 75200 & 59700 & 43400 & 30720 & 8900 \\
8 & 144000 & 101750 & 72975 & 56200 & 40775 & 24950 & 11900 \\
9 & 115000 & 96300 & 68750 & 47400 & 36750 & 23700 & 17300 \\
10 & 96300 & 74500 & 55800 & 42400 & 33200 & 25240 & 16200 \\
\hline
\end{tabular}

\section{Results}

Table I gives the range of plasma $\beta$ human chorionic gonadotrophin concentrations between two and 10 weeks after oocyte collection in ongoing singleton pregnancies achieved by in vitro fertilisation. Figure 2 shows plasma $\beta$ human chorionic gonadotrophin values in the set of ectopic pregnancies resulting from in vitro fertilisation when compared with ongoing singleton pregnancies. At each week from two to six weeks after oocyte collection circulating $\beta$ human chorionic gonadotrophin concentrations were significantly lower in ectopic than in normal pregnancies $(\mathrm{p}<0.00001$ at two weeks $v \mathrm{p}<0.01$ at six weeks; fig 2$)$. The highest $\beta$ human chorionic gonadotrophin concentration two weeks after oocyte collection in an ectopic pregnancy was $26.4 \mathrm{IU} / \mathrm{l}$. This was very close to the lower quartile value (25th percentile) of the concentration in the ongoing singleton pregnancies $(30.6 \mathrm{IU} / \mathrm{l})$. Accordingly, the lower quartile $\beta$ human chorionic gonadotrophin concentration in the ongoing pregnancies was assessed at each subsequent week to determine its value in diagnosing ectopic pregnancy.

Table II shows the predictive values of plasma $\beta$ human chorionic gonadotrophin concentrations in diagnosing ectopic pregnancies after in vitro fertilisation and embryo transfer two to six weeks after oocyte collection. Analyses of the data in table II by $\chi^{2}$ and G tests showed that the lower quartile value at each week after oocyte collection satisfactorily discriminated between ectopic pregnancy and other pregnancies $(p<0 \cdot 05)$. Using the 25th percentile value for ongoing singleton pregnancies as a discriminator showed that the sensitivity of this test was $100 \%$ at each week of gestation. The specificity of the test varied between $66 \%$ and $68 \%$. The predictive value of a plasma $\beta$ human chorionic gonadotrophin concentration above the 25th percentile (negative result) indicating an ongoing singleton pregnancy was $100 \%$, while the predictive value of a concentration below the 25th percentile for an ectopic pregnancy (positive result) varied between $4 \cdot 7 \%$ at six weeks and $16 \cdot 7 \%$ two weeks after oocyte collection. This predictive value was reflected in the percentage of false positive results for ectopic pregnancies at each week of gestation. For example, at two weeks after oocyte collection a $\beta$ human chorionic gonadotrophin concentration below the 25th pecentile for ongoing singleton pregnancies identified not only all of the subsequent ectopic pregnancies but also $18(66 \cdot 7 \%)$ of the cases destined for first trimester spontaneous abortion, 7 (58.3\%) of the cases of anembryonic pregnancy, plus none of the cases of multiple pregnancy. The efficiency of a plasma $\beta$ human chorionic gonadotrophin determination below the 25 th percentile for diagnosing an ectopic pregnancy resulting from in vitro fertilisation varied between $66 \%$ and $70 \%$ at each week after oocyte collection.

\section{Discussion}

In spontaneous pregnancies Lenton and Sulaiman found significant increases in circulating human chorionic gonadotrophin concentrations by 11 days after the mid-cycle peak of luteinising hormone. ${ }^{18}$ After this detection plasma human chorionic gonadotrophin concentrations rose with a doubling time of 1.3 days to reach concentrations between 50 and $250 \mathrm{IU} / 1$ at the time of the first missed period. The introduction of ultrasonography to gynaecology enabled investigators to determine the plasma human chorionic gonadotrophin concentrations at the time when a gestational sac could first be seen in the uterus of a patient with an intrauterine pregnancy. Kadar and colleagues suggested a discriminatory human chorionic gonadotrophin zone between 6000 and $6500 \mathrm{IU} / 1$ as the critical concentration at which a gestational sac should be seen within the uterus. ${ }^{7}$ Though this work was subsequently confirmed by the same group, ${ }^{8}$ other workers have suggested that a gestational sac is always seen when the plasma human chorionic gonadotrophin

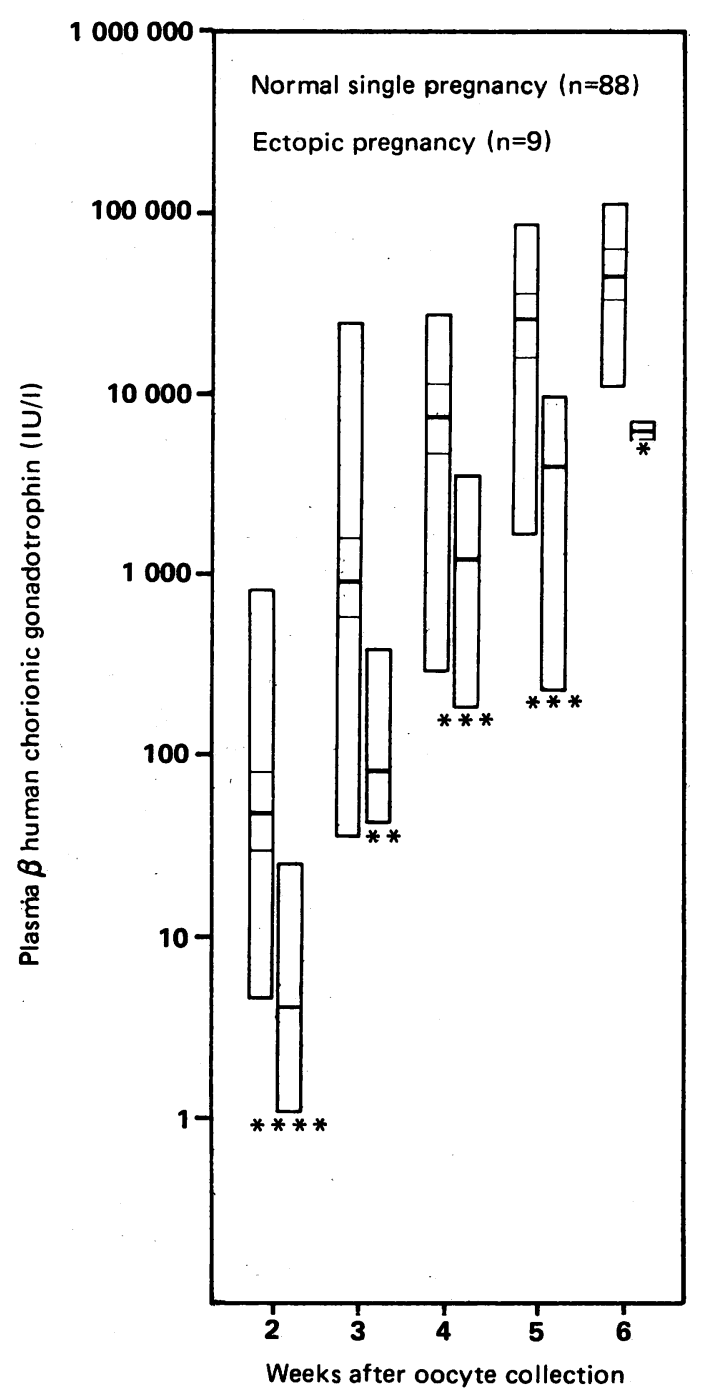

FIG 2-Plasma $\beta$ human chorionic gonadotrophin concentrations in singleton $(n=88)$ and ectopic $(n=9)$ pregnancies resulting from in vitro fertilisation. At each week ongoing singleton data are shown on the left. Heavy lines represent 50 th percentile and light lines 25 th and 75 th percentiles. Ectopic pregnancy data are shown on right at each week with 50 th centile (heavy line) and range of values displayed. ${ }^{\star} p<0.01 .{ }^{\star \star} p<0.005 .{ }^{\star \star \star} p<0.001 .{ }^{\star \star \star \star} p<0.00001$.

TABLE II-Predictive value and efficiency of plasma $\beta$ human chorionic gonadotrophin concentrations in diagnosing ectopic pregnancies after in vitro fertilisation and embryo transfer two to six weeks after oocyte collection. Figures are percentages

\begin{tabular}{ccccccc}
\hline $\begin{array}{c}\text { Weeks after } \\
\text { oocyte } \\
\text { collection }\end{array}$ & Sensitivity & Specificity & $\begin{array}{c}\text { Predictive } \\
\text { value of } \\
\text { positive } \\
\text { result }\end{array}$ & $\begin{array}{c}\text { Predictive } \\
\text { value of } \\
\text { negative } \\
\text { result }\end{array}$ & Efficiency & $\begin{array}{c}\text { False } \\
\text { positive rate }\end{array}$ \\
\hline $2^{\star}$ & 100 & $68 \cdot 1$ & $16 \cdot 7$ & 100 & $70 \cdot 0$ & $83 \cdot 3$ \\
3 & 100 & $66 \cdot 7$ & $8 \cdot 2$ & 100 & $67 \cdot 6$ & $91 \cdot 8$ \\
4 & 100 & $67 \cdot 6$ & $13 \cdot 7$ & 100 & $69 \cdot 2$ & $86 \cdot 3$ \\
5 & 100 & $68 \cdot 2$ & $10 \cdot 6$ & 100 & $69 \cdot 3$ & $89 \cdot 4$ \\
6 & 100 & $66 \cdot 1$ & $4 \cdot 7$ & 100 & $66 \cdot 7$ & $95 \cdot 3$ \\
\hline
\end{tabular}

* Only 150 subjects analysed at two weeks. Remaining 11 excluded from analysis at two weeks because they presented for $\beta$ human chorionic gonadotrophin testing on incorrect days. These patients subsequently bled at correct time. 
concentration is greater than $1800 \mathrm{IU} / 1 .{ }^{19}$ All these reports used real time or static ultrasound equipment applied to the patient's abdomen with a full bladder to provide a "transonic window" to allow the uterus to be examined. Variations in the quality of ultrasound imaging using these transabdominal techniques may explain the different results in the above reports. The recent description of transvaginal ultrasound imaging of the uterus may provide greater sensitivity for the early detection of an intrauterine gestational sac. ${ }^{20}$

Several reports have shown that the appearance of $\beta$ human chorionic gonadotrophin in the plasma is delayed in subjects who become pregnant after in vitro fertilisation as compared with women with spontaneous pregnancies. ${ }^{9}{ }^{1021}$ Moreover, in one report the size of the gestational sac resulting from in vitro fertilisation and embryo transfer was small in $36 \%$ of pregnancies ${ }^{22}$; a static ultrasound scanner was used together with an abdominal approach in that study. It is not clear why the appearance of $\beta$ human chorionic gonadotrophin is delayed in pregnancies resulting from in vitro fertilisation. Embryo growth in vitro is thought to be slower than in vivo, and possibly this might delay induction of the genes responsible for production of the $\alpha$ or $\beta$ subunits of human chorionic gonadotrophin. ${ }^{23}$ Englert and colleagues ${ }^{10}$ also suggested that the time lapse may be of embryonic origin, representing a delay of secretion, but also that it may result from delay in the establishment of embryomaternal vascular connections, so delaying secretion of human chorionic gonadotrophin from the embryo into the maternal circulation. We are currently investigating transvaginal ultrasound techniques to measure gestational sac size in pregnancies induced by in vitro fertilisation and to monitor a correlation with plasma human chorionic gonadotrophin concentrations in maternal blood.

Any screening method used to predict ectopic pregnancy must have a high sensitivity. Indeed, as ectopic pregnancy may be fatal, we believe that a valid system for assessing the risk of ectopic pregnancy should have a sensitivity greater than $90 \%$. We have used the 25 th percentile of plasma $\beta$ human chorionic gonadotrophin concentrations two weeks after oocyte collection to set a cut off point to assess our scoring method for risk of ectopic pregnancy. Table II shows that use of the 25 th percentile value at each week after oocyte collection maintained a $100 \%$ sensitivity for the diagnosis of ectopic pregnancy after in vitro fertilisation. Not surprisingly, the cut off point set for high sensitivity reduced the specificity of the test. Between two and six weeks after oocyte collection specificity ranged between $66 \%$ and $68 \%$, while the false positive rate varied between $83 \%$ and $95 \%$. We believe that such values are still clinically useful, since the initial plasma human chorionic gonadotrophin concentration below the 25 th percentile alerts the gynaecologist to the possibility of an ectopic pregnancy after in vitro fertilisation. Subsequent blood tests three and four weeks after oocyte collection will heighten or diminish this suspicion and enable the patient to be closely observed clinically several weeks before any ultrasonic or clinical evidence of ectopic pregnancy may arise. Furthermore, the conditions included in the differential diagnoses of an early failed pregnancy after in vitro fertilisation-spontaneous abortion and anembryonic pregnancy-cannot easily be resolved or prevented and are not a cause of maternal mortality or morbidity in the same sense as is an ectopic pregnancy.

We suggest that weekly measurement of plasma $\beta$ human chorionic gonadotrophin concentrations will reliably predict ectopic pregnancy after in vitro fertilisation. This method, using a discriminator based on the 25 th percentile for ongoing singleton pregnancies resulting from in vitro fertilisation, predicts ectopic pregnancy with high sensitivity. Clearly, repeated weekly $\beta$ human chorionic gonadotrophin estimations will provide much better predictive certainty than a single value and we suggest that weekly blood samples should be taken beginning two weeks after oocyte collection. This screening test for an ectopic pregnancy after in vitro fertilisation is cheap and would be available to most units offering in vitro fertilisation and embryo transfer. In our opinion such units should determine plasma $\beta$ human chorionic gonadotrophin concentrations in ongoing pregnancies resulting from in vitro fertilisation and use valid statistical analyses before applying these results to prediction of ectopic gestation. Whether human chorionic gonadotrophin is a more valid marker of ectopic pregnancy than is the measurement of other circulating proteins, such as pregnancy specific $\beta_{1}$ glycoprotein and pregnancy associated plasma protein $\mathrm{A}$, in either spontaneous pregnancies or those induced by in vitro fertilisation is still unclear..$^{24}$

We thank all members of the Monash University in vitro fertilisation programme, the secretariat, and Robyn Redman for their help. Professors Henry Burger and John Funder provided helpful criticism of the paper. SHO is supported by a fellowship from the Japan Educational Ministry.

\section{References}

1 Dorfman SF. Deaths from ectopic pregnancy. United States, 1979 to 1980. Obstet Gynecol 1983;62:334-8.

2 Strathy JH, Coulam CB, Marchbanks P, Annegers JF. Incidence of ectopic pregnancy in Rochester, Minnesota, 1950-1981. Obstet Gynecol 1984;64:37-43.

3 Steptoe PC, Edwards RG. Reimplantation of a human embryo with subsequent tubal pregnancy Lancet 1976; i:880-2.

4 Trounson AO, Leeton JF, Wood C, Webb J, Wood J. Pregnancies in humans by fertilization in vitro and embryo transfer in the controlled ovulatory cycle. Science 1981;212:681-2.

5 Australian In Vitro Fertilisation Collaborative Group. High incidence of preterm birth and early losses in pregnancy after in vitro fertilisation. $\mathrm{BrMed} \mathcal{f} 1985 ; 291: 1160-3$.

6 Confino E, Demir RH, Friberg J, Gleicher N. Predictive value of $\beta$-HCG levels in pregnancies achieved by in vitro fertilization and embryo transfer: an international collaborative study Fertil Steril 1986;45:526-31.

7 Kadar N, Devore G, Romero R. Discriminatory HCG zone: its use in the sonographic evaluation of ectopic pregnancy. Obstet Gynecol 1981;58:156-61.

8 Romero R, Kadar N, Jeanty P, et al. Diagnosis of ectopic pregnancy: value of the discriminatory human chorionic gonadotropin zone. Obstet Gynecol 1985;66:357-60.

9 Hay DL. Discordant and variable production of human chorionic gonadotrophin and its free $\alpha$ and $\beta$-subunits in early pregnancy. $\mathcal{F}$ Clin Endocrinol Metab 1985;61:1195-200.

10 Englert Y, Roger M, Belaisch-Allart J, Jondet M, Frydman R, Testart J. Delayed appearance of plasmatic chorionic gonadotropin in pregnancies after in vitro fertilization and embryo transfer. Fertil Steril 1984;42:835-40.

11 Chard T, Klopper A. Placental function tests. New York: Springer-Verlag, 1982:18-29.

12 Trounson A. In vitro fertilization. In: Martini L, James V, eds. Pregnancy and parturitioncurrent topics in experimental endocrinology. New York: Academic Press, 1982:44-73.

13 Okamoto S, Healy DL, Howlett DT, et al. An analysis of plasma estradiol concentrations during clomiphene citrate-human menopausal gonadotropin stimulation in an in vitro fertilizationembryo transfer program. 7 Clin Endocrinol Metab 1986;63:736-40.

14 Martinez F, Trounson A. An analysis of factors associated with ectopic pregnancy in a human in vitro fertilization program. Fertil Steril 1986;45:79-87.

15 Sokal RR, Rohlf FJ. Biometry: the principles and practice of statistics in biological research. New York: W H Freeman \& Co, 1981:99-126, 549-85.

16 Elveback LR, Guillier CL, Keating FR. Health, normality and the ghost of Gauss. $\mathcal{F} A M A$ 1970;211:69-75.

17 Galen RS, Gambino SR. Beyond normality: the predictive value and efficiency of medical diagnoses. New York: John Wiley \& Sons, 1975.

18 Lenton EA, Sulaiman R. Plasma concentrations of human chorionic gonadotrophin from the time of implantation until the second week of pregnancy. Fertil Steril 1982;37:773.

19 Nyberg DA, Filly RA, Mahony BS, Munro S, Laing FC, Jeffrey RB Jr. Early gestation: correlation of HCG levels and sonographic identification. American fourmal of Roentgenology 1985;144:954-8.

20 Dellenbach P, Nisand I, Moreau L, Feger B, Plumere C, Gerlinger P. Transvaginal sonographica controlled follicle puncture for oocyte retrieval. Fertil Steril 1985;44:656-62.

21 Lopata A, Martin M, Oliva K, Johnston I. Embryonic development and implantation following in vitro fertilization and embryo transfer. Fertil Steril 1982;38:682-7.

22 De Crespigny L, Robinson HP, Murphy A, et al. Gestation sac size in in vitro fertilization pregnancies. BrF Obstet Gynaecol 1985;92:953-7.

23 Naylor SL, Ching WW, Goodman HM, Lalley PA; Grzeschik KH, Sakaguchi AY. Chromosome assignment of genes encoding the $\alpha$ and $\beta$ subunits of glycoprotein hormones in man and mouse. Somatic Cell Genet 1983;9:757-70.

24 Westergaard JG, Teisner B, Sinosich MJ, Madsen LT, Grudzinska SJG. Does ultrasonic examination render biochemical test obsolete in the prediction of early pregnancy failure? $\mathrm{Br} \mathcal{F}$ Obstet Gynaecol 1985;92:77-83.

25 Sinosich MJ, Ferriera AN, Saunders DM. Monitoring of postimplantation embryo viability following successful in vitro fertilization and embryo transfer by measurement of placental proteins. Fertil Steril 1985;44:70-4.

(Accepted 19 January 1987)

Department of Obstetrics and Gynaecology and Centre for Early Human Development, Queen Victoria Medical Centre, and Medical Research Centre, Prince Henry's Hospital, Monash University, Melbourne, Australia

S H OKAMOTO, MD, clinical research fellow, department of obstetrics and gynaecology

D L HEALY, PHD, FRACOG, Wellcome Trust senior clinical research fellow, department of obstetrics and gynaecology and medical research centre

L M MORROW, BSC, research assistant, department of obstetrics and gynaecology

$P$ A W ROGERS, PHD, scientific director of in vitro fertilisation programme, department of obstetrics and gynaecology and centre for early human development

A O TROUNSON, PHD, director, centre for early human development

E C WOOD, FRCOG, FRACOG, deputy chairman, department of obstetrics and gynaecology

Correspondence to: Dr D L Healy, Monash Department of Obstetrics and Gynaecology, Queen Victoria Medical Centre, Melbourne 3000, Australia. 